\title{
Do ACE inhibitors offer specific benefits in the antihypertensive treatment of diabetic patients?
}

\section{7 years of unfulfilled promises}

\author{
P.T. Sawicki \\ Department of Metabolic Diseases and Nutrition, WHO Collaborating Centre for Diabetes, Heinrich-Heine-University \\ Düsseldorf, Germany
}

Six years after the synthesis of the first angiotensin converting enzyme inhibitor (ACEI) (SQ 14225, Captopril) in the laboratories of Cushman and Ondetti in 1975 [1], captopril was approved for marketing by the United States Food and Drug Administration for treatment of severe hypertension. In 1985 the indication for captopril and the second ACEI enalapril was expanded to include mild to moderate hypertension. In 1988 The Joint National Committee (JNC) recommended ACEI as one of the four firstline agents for treatment of hypertension [2]. However, because in 1993 any evidence that ACEI reduced the relevant end-points of antihypertensive therapy, i.e. stroke and myocardial infarction, was still lacking, JNC changed their recommendations. The JNC V recommendations suggest that thiazide diuretics and beta blockers be designated as drugs of first choice and ACEIs, calcium antagonists and alpha-receptor-blockers are alternative drugs, which should be reserved for special indications or when diuretics and beta blockers have been proved unacceptable or ineffective [3]. However, recent publications have suggested that these first-line antihypertensive drugs should be used restrictively in hypertensive diabetic patients [4-6], despite the fact that their proven benefit in reducing cardio- and cerebrovascular events both in patients with $[7,8]$ and without $[9$, 10] diabetes mellitus has been well-recognised in prospective, randomised intervention trials. Instead the use of ACEIs has been vigorously encouraged in diabetic patients [4-6], mostly because of their postulat-

Corresponding author: Dr. P.T. Sawicki, Department of Metabolic Diseases and Nutrition, Heinrich-Heine-University Düsseldorf, P.O.B. 101007, D-40001 Düsseldorf, Germany Abbreviations: ACEI, Angiotensin converting enzyme inhibitor; NIDDM, non-insulin-dependent diabetes mellitus; IDDM, insulin-dependent diabetes mellitus; GFR, glomerular filtration rate. ed advantage with regard to the reduction of urinary albumin excretion, no adverse effects on lipid levels or glycaemic control, and recently also the improvement of endothelial dysfunction.

\section{Do ACEIs improve endothelial dysfunction?}

Currently, the relationship between diabetes, insulin resistance, hypertension and endothelial function is receiving a great deal of attention [11, 12]. As suggested previously, and also in this issue of Diabetologia by Dr. Gazis et al., the vasodilating properties of insulin have been shown to be mediated via an increase in nitric oxide production $[13,14]$, and to be reduced in insulin resistant states such as essential hypertension [15], obesity [16], and non-insulin-dependent diabetes $[16,17]$. Also, chronic experimental hypertension and essential hypertension are associated with an attenuated endothelium-dependent relaxation to different vasodilatory stimuli, which improves with lowering of blood pressure $[18,19]$. Therefore, any specific effect of ACEIs on endothelium-dependent relaxation has to be controlled for the blood pressure lowering effect of these agents. Hence, an adequate study design, even in normotensive patients, would require the comparison between an ACEI and another antihypertensive agent, since the risk of vascular damage starts to rise below the arbitrary blood pressure limit of 140/90 $\mathrm{mm} \mathrm{Hg}$.

In hypercholesterolaemic rabbits, administration of the ACEI ramipril retarded the progression of atherosclerosis when compared to the no-antihypertensive-drug group [20]. However, endothelium-dependent relaxation to acetylcholine was not significantly different between ramipril and the calcium antagonist isradipine, and both drugs prevented the reduction of basal endothelium-derived relaxing factor/nitric oxide [20]. In SHR rats, administration of 
the ACEI cilazapril significantly enhanced the acetylcholin-induced relaxation, while the direct vasodilator hydralazine had no effect [21]. However, this result cannot be taken as proof of a blood pressure independent effect of ACEIs, because blood pressure control was significantly different between both groups: mean systolic blood pressure was $171 \mathrm{~mm} \mathrm{Hg}$ in the hydralazine group and $124 \mathrm{~mm} \mathrm{Hg}$ in the cilazapril group. In a non-blind, non-randomised study [22] in seven hypertensive patients acute administration of $25 \mathrm{mg}$ of captopril lowered mean blood pressure and augmented the low-dose acetylcholine-induced forearm vasodilatation. No effect of captopril was found with high-dose acetylcholine and with nitroprusside [22]. In this study nifedipine also resulted in an improved vasodilatation with low dose acetylcholine, but this effect was statistically not significant, probably due to the investigation of only five hypertensive patients in the nifedipine group [22]. In addition, no power analysis and no statistical comparisons between captopril and nifedipine were reported [22].

To resolve the question of whether the ACEI quinapril could ameliorate coronary endothelial dysfunction in normotensive patients with coronary artery disease with ejection fraction above $40 \%$ undergoing a revascularisation procedure, the TREND study (Trial on Reversing ENdothelial Dysfunction) has been designed [23]. However, the study also included non-normotensive patients with blood pressure values below 162/92 $\mathrm{mm} \mathrm{Hg}$, patients with a history of controlled hypertension and patients with a history of myocardial infarction. Quinapril reduced the degree of acetylcholine-induced coronary vasoconstriction when compared to placebo. However, blood pressure values were not comparable between the groups. Despite randomisation the quinapril group showed at baseline significantly lower mean systolic blood pressure values $119 \mathrm{~mm} \mathrm{Hg}$ when compared to placebo $127 \mathrm{~mm} \mathrm{Hg}, p=0.007$, and, most surprisingly, treatment with quinapril significantly increased blood pressure values by $13.5 \mathrm{~mm} \mathrm{Hg}$ $(p=0.014)$. This paradoxical effect of quinapril on blood pressure and the fact that the amelioration of the impaired coronary vasomotor function persisted after cessation of oral therapy for at least 3 days, calls for additional explanations besides the short lasting blockage of the locally generated tissue angiotensin II. Non-specific effects such as improvement in ventricular dysfunction, alteration of sympathetic nerve activity [24] or enhancement of baroreceptor reflex sensitivity [25] could also have played a role.

In diabetic patients three studies examined the effect of ACEIs on endothelial function. In a study of 10 non-insulin-dependent hypertensive patients, 6 months' treatment with the ACEI perindopril reduced blood pressure but did not improve endothelium-dependent vasodilation as assessed by three different stimuli [26]. In a preliminary report of a rando- mised cross-over study in uncomplicated insulin-dependent diabetic patients, 5 weeks' of quinapril administration reduced mean arterial blood pressure but the effect on endothelium-dependent vasodilatation was not significantly different from placebo [27]. Another recent preliminary report described a significantly impaired hyperaemic response and reduced foot oxygen tension in insulin-dependent (IDDM) and non-insulin-dependent (NIDDM) diabetic patients when compared to healthy control subjects [28]. In this study 6 months of treatment with the ACEI trendolapril had no effect on either parameter of vascular dysfunction as compared to placebo [28].

Until now it has not been clarified whether druginduced changes in the endothelium-dependent relaxation to different stimuli are associated with improved prognosis for diabetic patients. In addition, to date there is still no evidence that ACEIs indeed improve endothelial function in diabetic patients. Vascular reactivity in diabetes represents a fascinating and controversial area of research. However, before diabetic patients with endothelial dysfunction are treated with any agent, its beneficial effect on the valid clinical end-points, i.e. morbidity and mortality has to be demonstrated first.

\section{Do ACEIs improve the prognosis of hypertensive diabetic patients?}

Cardiovascular events. The prognosis of hypertensive IDDM and NIDDM patients depends mainly on the risk of cardiovascular events. Conventional antihypertensive treatment with beta blockers and diuretics has been convincingly shown to reduce cardio- and cerebrovascular morbidity and mortality. Also, more than ten major studies have shown beyond any doubt that ACEI treatment improves survival in patients with clinical heart failure with and without myocardial infarction. However, most astonishingly, to date the effect of antihypertensive treatment with ACEIs on cardio- and cerebrovascular events has never been investigated in hypertensive diabetic or nondiabetic patients. Instead the superiority of these antihypertensive agents over the conventional antihypertensive therapy with regard to "soft" (surrogate) end-points has been repeatedly proposed. It has been reiterated that the conventional antihypertensive treatment may have untoward effects on glucose and lipid metabolism and thereby counterbalance the positive blood pressure lowering effect, especially in diabetic patients [29]. These negative metabolic effects of the cheaper conventional antihypertensive agents have been repeatedly stressed particularly during industry-organised and largely promotional "educational" events [30]. However, recently it has been well-recognised that the treatment with cardioselective beta blockers and low-dose thiazide diure- 
Table 1. Overview of controlled, randomised, prospective studies of at least 2 years' duration with different ACEIs in IDDM patients with diabetic nephropathy, and reporting the

\begin{tabular}{|c|c|c|c|}
\hline Study & $\begin{array}{l}\text { Decline of GFR in } \\
\text { the ACEI group } \\
\left(\mathrm{ml} \cdot \min ^{-1} \cdot \text { year }\right. \\
\end{array}$ & $\begin{array}{l}\text { Decline of GFR in } \\
\text { the control group } \\
\left(\mathrm{ml} \cdot \min ^{-1} \cdot \text { year }^{-1}\right)\end{array}$ & Comments \\
\hline Björck et al. 1992 [44] & Enalapril - 2 & Metoprolol - 6 & $\begin{array}{l}\text { - Significantly lower blood pressure values in the ACEI group } \\
\text { - No linear course of GFR in the ACEI group } \\
\text { - Exclusion of patients with rise in serum creatinine from the } \\
\text { ACEI group }\end{array}$ \\
\hline Bauer et al. 1993 [42] & Enalapril - 13 & Placebo -8 & $\begin{array}{l}\text { - Patients with NIDDM also included } \\
\text { - No linear course of GFR in the ACEI group }\end{array}$ \\
\hline Lewis et al. 1993 [45] & Captopril - 9 & Placebo - 13 & $\begin{array}{l}\text { - Significantly lower blood pressure values in the ACEI group } \\
\text { - Randomisation failure: significantly lower baseline albumi- } \\
\text { nuria in the ACEI group }\end{array}$ \\
\hline Elving et al. 1994 [46] & Captopril - 5 & Atenolol - 4 & $\begin{array}{l}\text { - Similar blood pressure control between the groups } \\
\text { - } 95 \% \text { probability of excluding difference of more than } 50 \% \\
\text { between the groups }\end{array}$ \\
\hline Sawicki et al. 1997 [47] & Ramipril + 1 & Metoprolol \pm 0 & $\begin{array}{l}\text { - Similar blood pressure control between the groups } \\
\text { - All patients treated with intensified insulin and intensified } \\
\text { antihypertensive therapy }\end{array}$ \\
\hline
\end{tabular}

decline of kidney function measured by the loss of GFR per year $\left(\mathrm{ml} \cdot \min ^{-1} \cdot\right.$ year $\left.^{-1}\right)$
- No linear course of GFR in the ACEI group

Exclusion of patients with rise in serum creatinine from the

No linear course of GFR in the ACEI group

nuria in the ACEI group

$95 \%$ probability of excluding difference of more than $50 \%$

- Similar blood pressure control between the groups antihypertensive therapy tics does not result in a clinically relevant increase in cholesterol levels [30-32] and does not impair glycaemic control [31-33]. To describe the relevant endpoints of antihypertensive treatment with conventional antihypertensive agents, a subgroup analysis of a large prospective intervention trial in patients with systolic hypertension has been performed [8]. The study comprised 583 NIDDM patients and 4149 non-diabetic patients with systolic hypertension who had been randomised to receive a low-dose diuretic agent chlorthalidone, along with the cardioselective beta blocker atenolol. Outcome rates included cardiac events, stroke and mortality. Not only was the conventional antihypertensive treatment effective in reducing the study events in diabetic patients, but the benefit was twice as great as in non-diabetic patients, resulting in an absolute risk reduction of 101 events per 1000 study participants with diabetes and 51 events per 1000 study participants without diabetes. Hence, probably because of a higher baseline risk, conventional antihypertensive treatment offers greater benefit to diabetic patients in terms of numbers needed to treat when compared to non-diabetic hypertensive patients. On the other hand a randomised, double-blind, prospective study described a surprising excess in mortality in NIDDM patients treated with the ACEI captopril as compared to conventional antihypertensive therapy with hydrochlorothiazide and metoprolol [34]. Also, in a randomised, prospective, double-blind study an increased incidence of vascular events was described in patients treated for hypertension with the metabolically neutral calcium channel blocker isradipine as compared to the diuretic agent hydrochlorothiazide [35]. In this study, the risk of having a cardiovascular event increased with the glycosylated haemoglobin
$\left(\mathrm{HbA}_{1 \mathrm{c}}\right)$ values in the isradipine group but not in the diuretic group [36]. Thus, antihypertensive agents may differ with regard to their effect on cardiovascular events, and therefore evidence for safety and effectivity of any new agent group including ACEIs is needed, before it can be recommended as the firstline antihypertensive treatment.

Diabetic nephropathy. There is no doubt that blood pressure reduction with and without ACEIs delays the progression of nephropathy. The open question is however, whether ACEI treatment results in a greater benefit for the diabetic kidney when compared to conventional antihypertensive treatment, or, in other words, whether ACEIs have specific kidney-protective properties to slow the progression of diabetic nephropathy, i. e. over and above their antihypertensive effect. In meta-analyses including controlled and uncontrolled studies, ACEIs have been reported to be more effective than other antihypertensive agents with regard to the reduction of albuminuria and proteinuria [37], but equally effective with regard to their influence on the decline of glomerular filtration rate (GFR) in diabetic nephropathy [38]. In this context it must be stressed that the change in urinary albumin excretion is often falsely taken as a measure of progression of renal disease [39]. ACEIs may decrease albuminuria in diabetic glomerulopathy by modulating the intrinsic glomerular basement membrane properties [40,41] without necessarily influencing the decline of GFR. Recently, in two intervention studies in diabetic nephropathy, treatment with ACEIs resulted in both a significant decrease of albuminuria and a faster loss of GFR when compared to placebo [42] or a calcium channel blocker [43]. Table 1 shows an overview of currently 
published randomised controlled trials in diabetic nephropathy of at least 2 years' duration. It becomes clear that several methodological problems limit the value of some of these studies. Especially in both studies which showed an advantage of ACEI treatment $[44,45]$ on the decline of GFR, blood pressure was lowered more in the ACEI groups. Thus, there is still no evidence for a specific, i.e. blood pressure independent, beneficial effect of ACEIs on the progression of diabetic nephropathy as measured by the decline of GFR.

Most importantly, the investigation of antihypertensive agents in patients with diabetic nephropathy should not only be restricted to the change in GFR, but also take into account their effect on the reduction of the severely increased cardiovascular mortality and morbidity in these patients. In a long-term prospective intervention study we have demonstrated that an intensification of antihypertensive treatment with first-line therapy based upon cardioselective beta blockers and diuretics in IDDM patients with diabetic nephropathy is associated not only with a reduction of the progression of nephropathy and retinopathy by also with a major improvement in life expectancy [48]. The only other prospective controlled study, which reported the impact of antihypertensive therapy on survival in diabetic nephropathy [45] failed to demonstrate a significant reduction of mortality with ACEI treatment. In addition, recently, treatment with the ACEI benazapril in nephropathic patients including diabetic nephropathy resulted in a significant increase in total mortality [49]. Hence, studies comparing the effect of different antihypertensive agents on cardiovascular mortality in diabetic nephropathy are urgently needed. As proposed more than 35 years ago, if there is a treatment of accepted value (antihypertensive therapy) the doctor will wish to know whether a new treatment (ACEIs) is more or less effective than the conventional (beta blockers and diuretics), and not whether it is more effective than placebo [50].

Despite their availability for more than 17 years the safety and effectivity of antihypertensive therapy with ACEIs in hypertensive diabetic and non-diabetic patients with regard to valid clinical end-points has not been adequately demonstrated in prospective controlled trials. The repeatedly published proposals of additional putative concepts, how these agents might possibly improve the prognosis of diabetic patients, cannot compensate this scientific shortcoming. Fortunately, finally after 20 years of use of ACEIs, studies will be completed to provide valid answers to these questions [32, 51-53], but, let us be more prudent next time and define optimal treatment strategies earlier when new agents emerge.

\section{References}

1. Cushman DW, Ondetti MA (1991) History of the design of captopril and related inhibitors of angiotensin-converting enzyme. Hypertension 17: 589-592

2. Joint National Committee (1988) The 1988 report of the Joint National Committee on detection, evaluation, and treatment of high blood pressure. Arch Intern Med 148: $1023-1038$

3. Joint National Committee (1993) The fifth report of the Joint National Committee on detection, evaluation, and treatment of high blood pressure (JNC V). Arch Intern Med 153: 154-183

4. American Diabetes Association (1997) Diabetic nephropathy. Diabetes Care 20 [Suppl 1]: S24-S27

5. Kaplan NM, Rosenstock J, Raskin P (1987) A differing view of treatment of hypertension in patients with diabetes mellitus. Arch Intern Med 147: 1160-1162

6. Anonymous. Consensus statement (1993) Treatment of hypertension in diabetes. Diabetes Care 10: 1394-1401

7. The Hypertension Detection and Follow-up Programme Co-operative Research Group (1985) Mortality findings for stepped-care and referred care participants in the Hypertension Detection and Follow-up Programme, stratified by other risk factors. Prev Med 14: 312-335

8. Curb JD, Pressel SL, Cutler JA et al. for the Systolic Hypertension in the Elderly Program Co-operative Research Group (1996) Effect of diuretic-based antihypertensive treatment on cardiovascular disease risk in older diabetic patients with isolated systolic hypertension. JAMA 276: 1886-1892

9. Collins R, Peto R (1994) Antihypertensive drug therapy: effects on stroke and coronary heart disease. In: Swales JD (ed) Textbook of hypertension. Blackwell, Oxford, pp 1156-1164

10. World Health Organisation (1996) Hypertension Control. Report of a WHO expert committee. World Health Organisation, Geneva

11. Feener EP, King GL (1997) Vascular dysfunction in diabetes mellitus. Lancet 350: [Suppl 1]: 9-13

12. Baron AD, Steinberg HO (1997) Endothelial function, insulin sensitivity, and hypertension. Circulation 96: 725-726

13. Polderman KH, Stehouwer CDA, van Kamp GJ, Gooren LJG (1996) Effects of insulin on endothelium-derived vasoactive substances. Diabetologia 39: 1284-1292

14. Steinberg HO, Brechtel G, Johnson A, Fineberg N, Baron AD (1994) Insulin-mediated skeletal muscle vasodilation is nitric oxide dependent - a novel action of insulin to increase nitric oxide release. J Clin Invest; 94: $1172-1179$

15. Forte P, Copland M, Smith LM, Milne E, Sutherland J, Benjamin N (1997) Basal nitric oxide synthesis in essential hypertension. Lancet 349: 837-842

16. Laakso M, Edelman SV, Brechtel G, Baron AD (1992) Impaired insulin-mediated skeletal muscle blood flow in patients with NIDDM. Diabetes 41: 1076-1083

17. Williams SB, Cusco JA, Roddy MA, Johnstone MT, Creager MA (1996) Impaired nitric oxide-mediated vasodilation in patients with non-insulin-dependent diabetes mellitus. J Am Coll Cardiol 27: 567-574

18. Lüscher TF, Raij L, Vanhoutte PM (1987) Endotheliumdependent responses in normotensive and hypertensive Dahl rats. Hypertension 9: 157-163

19. Panza JA, Ouyyumi AA, Brusch JE Jr, Epstein SE (1990) Abnormal endothelium-dependent vascular relaxation in patients with essential hypertension. N Engl J Med 323: $22-27$ 
20. Rizebos J, Vleeming W, Beems RB et al. (1994) Comparison of the antiatherogenic effects of isradipine and ramipril in cholesterol-fed rabbits: I. Effect on progression of atherosclerosis and endothelial dysfunction. J Cardiovasc Pharmacol 23: 415-423

21. Clozel M, Kuhn H, Hefti F (1990) Effects of angiotensin converting enzyme inhibitors and of hydralazine on endothelial function in hypertensive rats. Hypertension 16: 532-540

22. Hirooka Y, Imaizumi T, Masaki H et al. (1992) Captopril improves impaired endothelium-dependent vasodilation in hypertensive patients. Hypertension 20: 175-180

23. Mancini J, Henry GC, Macaya C et al. (1996) Angiotensinconverting enzyme inhibition with quinapril improves endothelial dysfunction in patients with coronary artery disease. The TREND (Trial on Reversing ENdothelial Dysfunction) Study. Circulation 94: 258-265

24. Papageorgiou A, Karayiannis A, Athyros V, Douma S, Petidis K, Zamboulis C (1994) Comparative study of the efficacy and safety of quinapril versus lisinopril in patients with mild to moderate essential hypertension. Drug Invest 7: $13-17$

25. Osterziehl KJ, Rohring N, Dietz R, Manthey J, Hecht J, Kuber W (1988) Influence of captopril on the arterial baroreceptor reflex in patients with heart failure. Eur Heart J 9: 1137-1145

26. Bijlstra PJ, Smits P, Lutterman JA, Thien TH (1995) Effect of long term angiotensin-converting enzyme inhibition on endothelial function in patients with insulin-resistance syndrome. J Cardiovasc Pharmacol 25: 658-664

27. Smulders RA, Lambert J, Aarsen M, Donker AJM, Stehouwer CDA (1995) The effect of ACE-inhibition on endothelial function in uncomplicated insulin dependent diabetic subjects. Diabetologia 38 [Suppl 1]: A49 (Abstract)

28. Malik RA, Williamson S, Abbott C, Boulton AJM (1997) ACE inhibition fails to improve reduced oxygen tension and the impaired hyperaemic response in diabetic patients: a placebo-controlled clinical trial. Diabet Med 14: S30

29. Warram JH, Laffel LMB, Vasania P, Christlieb AR, Królewski AS (1991) Excess mortality associated with diuretic therapy in diabetes mellitus. Arch Intern Med 151: $1350-1356$

30. Moser M, Blaufox MD, Freis E et al. (1991) Who really determines your patients' prescriptions? JAMA 265: 498-500

31. Sawicki PT, Mühlhauser I, Baba T, Berger M (1990) Do angiotensin converting enzyme inhibitors represent a progress in hypertension care in diabetes mellitus? Diabetologia 33: $121-124$

32. Hypertension in Diabetes Study Group (1996) Hypertension in Diabetes Study IV. Therapeutic requirements to maintain tight blood pressure control. Diabetologia 39: 1554-1561

33. Harper R, Ennis CN, Heaney AP et al. (1995) A comparison of the effects of low and conventional-dose thiazide diuretics on insulin action in hypertensive patients with NIDDM. Diabetologia 38: 853-859

34. Lacourcière Y, Nadeau A, Poirier L, Tancède G (1993) Captopril or conventional therapy in hypertensive type 2 diabetics. Three-year analysis. Hypertension 21: 786-794

35. Borhani NO, Mercuri M, Borhani PA et al. (1996) Final outcome results of the multicenter isradipine diuretic atherosclerosis study (MIDAS). A randomised controlled trial. JAMA 276: 785-791
36. Byington RP, Craven TE, Furberg CD, Pahor M (1997) Isradipine, raised glycosylated haemoglobin, and risk for cardiovascular events. Lancet 350: 1075-1076

37. Weidmann P, Boehlen M, de Courten M (1993) Effects of different antihypertensive drugs on human proteinuria. Nephrol Dial Transplant 8: 582-584

38. Parving HH, Rossing P (1994) The use of antihypertensive agents in prevention and treatment of diabetic nephropathy. Current Opinion in Nephrology and Hypertension 3: 292-300

39. The EUCLID study group (1997) Randomised placebocontrolled trial of lisinopril in normotensive patients with insulin-dependent diabetes and normoalbuminuria or microalbuminuria. Lancet 349: 1787-1792

40. Morelli E, Loon N, Meyer T, Peters W, Myers BD (1990) Effects of converting-enzyme inhibition on barrier function in diabetic glomerulopathy. Diabetes 39: 76-82

41. Sawicki PT, Berger M (1994) Measuring progression of diabetic nephropathy. Review. Eur J Clin Invest 24: 651-655

42. Bauer JH, Reams GP, Hewett J et al. (1992) A randomised, double-blind, placebo-controlled trial to evaluate the effect of enalapril in patients with clinical diabetic nephropathy. Am J Kidney Dis 20: 443-457

43. Rossing P, Tarnow L, Boelskifte S, Jensen BR, Nielsen FS, Parving HH (1997) Differences between nisoldipine and lisinopril on glomerular filtration rates and albuminuria in hypertensive IDDM patients with diabetic nephropathy during the first year of treatment. Diabetes 46: 481-487

44. Björck S, Mulec H, Johnsen SA, Norden G, Aurell M (1992) Renal protective effect of enalapril in diabetic nephropathy. BMJ 304: 339-342

45. Lewis EJ, Hunsicker LG, Bain RP, Rohde RD (1993) The effect of angiotensin-converting-enzyme inhibition on diabetic nephropathy. New Engl J Med 329: 1456-1462

46. Elving LD, Wetzels JMF, van Lier HJJ, de Nobel E, Berden JHM (1994) Captopril and atenolol are equally effective in retarding progression of diabetic nephropathy. Diabetologia 37: 604-609

47. Sawicki PT, for the Diabetes Teaching and Treatement Programmes Working Group (1997) Stabilisation of glomerular filtration rate over 2 years in patients with diabetic nephropathy under intensified therapy regimens. Nephrol Dial Transplant 12: 1890-1899

48. Sawicki PT, Mühlhauser I, Didjurgeit U, Baumgartner A, Bender R, Berger M (1995) Intensified antihypertensive therapy is associated with improved survival in type 1 diabetic patients with nephropathy. J Hypertens 13: 933-938

49. Maschio G, Alberti D, Janin G et al. and the AngiotensinConverting-Enzyme Inhibition in Progressive Renal Insufficiency Study Group (1996) The effect of the angiotensinconverting-enzyme inhibitor benazapril on the progression of chronic renal insufficiency. N Engl J Med 334: 939-945

50. Hill AB (1963) Medical ethics and controlled trials. BMJ 1: 1043-1049

51. Davis BR, for the ALLHAT Research Group (1996) Rationale and design for the Antihypertensive and Lipid Lowering treatment to prevent Heart Attack Trial (ALLHAT). Am J Hypertens 9: 342-360

52. Passa P, Chatellier G (1996) The DIAB-HYCAR Study. Diabetologia 39: 1662-1667

53. Schrier RW, Estacio RO, Jeffes B (1996) Appropriate blood pressure control in NIDDM (ABCD) trial. Diabetologia 39: 1662-1667 